\title{
Improving the Quality of Surfaces Finished by Lapping by Robust Parameter Design
}

\author{
Andrea Deaconescu and Tudor Deaconescu, Member, IACSIT
}

\begin{abstract}
Obtaining special quality surfaces as well as higher dimensional and geometrical precision entails deployment of surface smoothing processes, one of which is lapping. A lapping process is strongly influenced by a number of input parameters, the most important ones being machining speed, pressure, duration of lap plate - abrasive paste workpiece contact, kinematics of the machine-tool etc. The paper presents a study on the influence of machining speed in lapping on the roughness of metal surfaces.
\end{abstract}

Index Terms-Lapping, machining speed, robust design, roughness.

\section{INTRODUCTION}

One of the elements defining product quality is the degree of finishing of workpiece surfaces. For this reason special emphasis needs to be placed on the study of surface smoothing processes, given their decisive role in determining high dimensional and geometric precisions.

One of the most widespread surface smoothing processes is lapping. Lapping operates by abrasive erosion, the tooling allowance being removed by means of grains located at the transfer object (lap plate) and workpiece interface. Lapping falls into the category of cutting processes deploying tools with undefined cutting edges. It is a final processing method where the abrasive grains are freely dispersed in a holding fluid, while cutting is conducted typically by a form transmitting counter-part known as transfer object. Fig. 1 presents the principle of surface lapping.

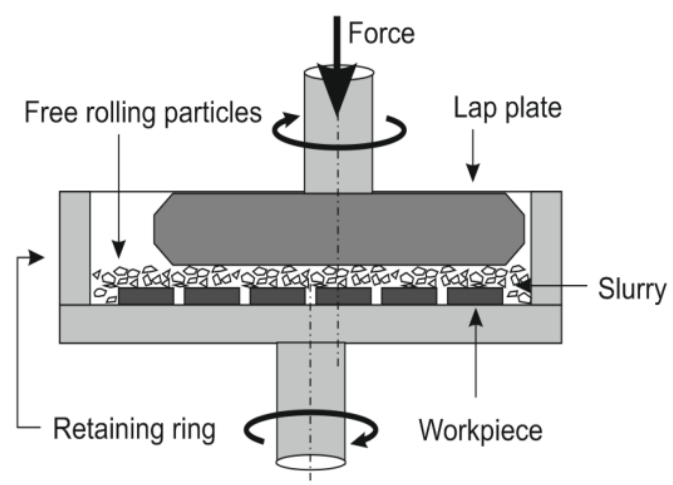

Fig. 1. Principle of lapping.

The tooling allowance is removed by inducing a relative motion between the lap plate and the workpiece in the presence of slurry, consisting of abrasive powder in

Manuscript received March 18, 2013; revised June 13, 2013

The authors are with the Transilvania University of Braşov, Romania (phone/fax: 0040268 477113; e-mail: deacon@unitbv.ro, tdeacon@unitbv.ro). suspension in a fluid. For erosion to take place, a certain pressure generated by a downward oriented force is required between the lap plate and the workpieces.

Compared to other surface machining processes, lapping stands out by a number of characteristics:

1) Highest requirements related to planeness and roughness can be satisfied;

2) The reduced heat quantity developed during machining influences the structure of the superficial layer only to a small;

3) Lapped surfaces retain minimal stress and are burr-free;

4) Most workpieces can be machined without special clamping devices;

5) Several parts can be machined simultaneously.

Lapping processes are strongly influenced by numerous input parameters, the most important ones being machining speed, pressure, duration of lap plate - abrasive paste workpiece contact, kinematics of the machine-tool etc.

Lapping speed is one of the working parameters with particular impact on obtaining small roughness surfaces with a superficial layer as little as possible affected thermally. Compared to other machining processes, lapping involves smaller speeds, between 20 and $150 \mathrm{~m} / \mathrm{min}$. The smaller speed values of this range $(20 \ldots 40 \mathrm{~m} / \mathrm{min})$ are used for finishing, while the greater ones are applicable for preliminary lapping. Excessive increase of the machining speed causes an overheating of the processed surface and a diminishing of its quality [1].

Experiments confirmed that machining productivity increases with speed. This increase in productivity is however not unlimited, as with growing lap plate speed the centrifugal forces reach values that cause the abrasive slurry to be evacuated from the working area. Too high cutting speeds further affect the planeness of the machined surface, as a consequence of uneven distribution of the lapping paste in the working gap [2].

The paper presents further an analysis of lapped surface roughness variation versus machining speed.

\section{WORKING EQUIPMENT}

Experimental research was conducted on a specially developed device adapted to FUS 22 milling machine. Testing concerned plane lapping of workpieces made from various categories of materials (heat treated by cementing and annealing, respectively). The surface roughness $\left(R_{a}\right)$ was measured, of workpieces made from: 18MoCr10, 38MoCr09 and 50WCr11.

Fig. 2 presents the schematic and a view of the lapping device [3]. 

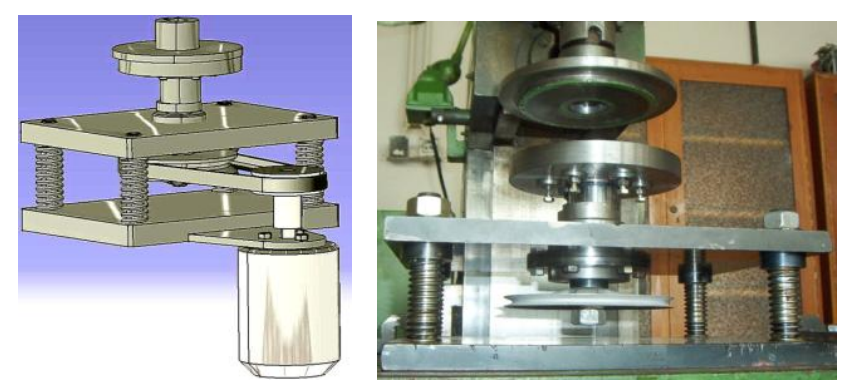

Fig. 2. Schematic and view of the device.

The inferior plate of the lapping device is clamped to the machine table by means of brackets. The upper plate can glide along four cylindrical pillars and is maintained in its superior limit position by four springs. On this upper plate a rotating retaining ring is mounted, with seats that can ensure the simultaneous machining of up to six workpieces. The retaining ring can be positioned with an eccentricity adjustable between 0 and $6 \mathrm{~mm}$ in relation to the rotation axis of the device shaft.

The working pressure is achieved by lifting of the machine table together with the entire lapping device. Thus, upon achieving contact between the lap plate and the workpieces the helical springs are compressed and a continuously adjustable pressure is obtained, depending on the deformation of the springs.

The lap disk is set into rotation from the vertical main shaft of the milling machine. The possible speeds of the lap disks are determined by the gearbox of the milling machine. The speeds used in the discussed research were of $63 \mathrm{rpm}$ and 100 rpm.

The retaining ring bearing the workpieces also carries out a rotation, in the same or opposite direction to the lap disk, being driven by a d.c. motor via a V-belt. The speed of the retaining ring can be continuously adjusted in the range of $0 \ldots 1400 \mathrm{rpm}$, by adjusting the feed voltage between 0 and $30 \mathrm{~V}$.

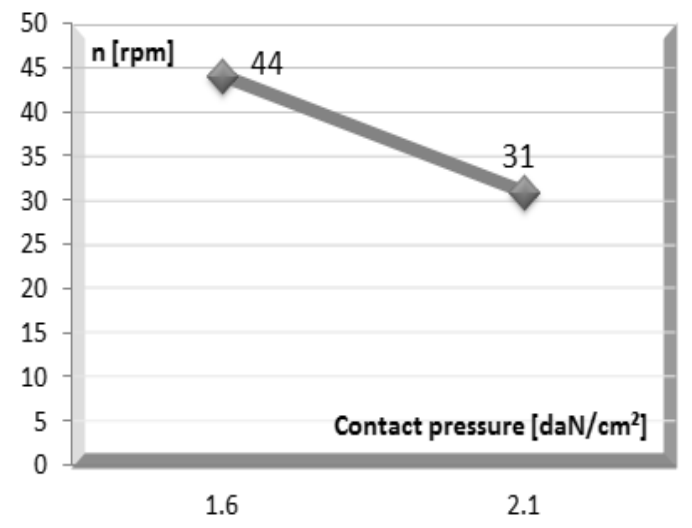

Fig. 3. Mechanical characteristic of the d.c. motor

TABLE I: RELATIVE SPEEDS USED FOR PLANE LAPPING

\begin{tabular}{cccc}
\hline \hline $\begin{array}{c}\text { Working } \\
\text { pressure } \\
{\left[\mathrm{daN} / \mathrm{cm}^{2}\right]}\end{array}$ & $\begin{array}{c}\text { Lap disk speed } \\
\mathbf{r r p m}]\end{array}$ & $\begin{array}{c}\text { Retaining ring } \\
\text { speed } \\
{[\mathrm{rpm}]}\end{array}$ & $\begin{array}{c}\text { Relative speed } \\
\leftrightarrows \\
{[\mathrm{m} / \mathrm{min}]}\end{array}$ \\
\hline \multirow{2}{*}{1.6} & 63 & 44 & 30.23 \\
& 100 & 31 & 40.69 \\
2.1 & 63 & 31 & 26.56 \\
& 100 & & 37.3 \\
\hline
\end{tabular}

Fig. 3 presents the mechanical characteristic of the motor driving the retaining $\operatorname{ring}(U=5.5 \mathrm{~V})$. Based on this characteristic the relative machining speed can be calculated, that is the relative speed of lap disk and workpieces. Table I features the relative speeds calculated with a known display radius of the workpieces in the retaining ring $(r=45 \mathrm{~mm})$ for opposite rotation directions of lap disk and retaining ring.

\section{RoBUSt PARAMETER DESIGN OF THE MACHINING SYSTEM}

The method of robust parameter design proved useful in many types of machining, and has been applied, as discussed further on, for the study of plane surface lapping. The aim of this study is to investigate systematically the effects of different lapping parameters on the roughness of the machined surface.

TABLE II: SELECTED FACTORS AND SET POINTS

\begin{tabular}{|c|c|c|c|c|c|}
\hline \multirow[b]{3}{*}{ Set point } & \multicolumn{5}{|c|}{ Factors } \\
\hline & $\mathrm{A}$ & B & $\mathrm{C}$ & $\mathrm{D}$ & $E$ \\
\hline & $\begin{array}{c}\text { Eccentricity } \\
{[\mathrm{mm}]}\end{array}$ & $\begin{array}{c}\text { Abrasive concentration } \\
{[\%]}\end{array}$ & $\begin{array}{c}\text { Speed of lap disk } \\
{[\mathrm{rpm}]}\end{array}$ & $\begin{array}{c}\text { Contact pressure } \\
\text { [bar] }\end{array}$ & $\begin{array}{l}\text { Duration of machining } \\
\text { [min] }\end{array}$ \\
\hline 1 & 6 & 5 & 100 & 2.1 & 4 \\
\hline 2 & 3 & 10 & 63 & 1.6 & 3 \\
\hline 3 & - & - & - & - & 5 \\
\hline
\end{tabular}

Optimisation of the lapping process was achieved by the method of fractioned orthogonal factorial arrays of experiments devised by G. Taguchi. It is Taguchi's merit to have provided a strategy that, instead of identifying and eliminating noise factors affecting the operation of the machining system, aims at minimizing their impact. Concretely, the strategy consists in identifying those combinations of input parameter set points that will reduce the effects of noises, without however, addressing these directly.

For this, five factors were selected from the numerous input quantities that affect the lapping process, namely those factors whose contribution to the machining process is considered as major [4], [5]. Table II presents these factors, with the 2 or 3 set points considered for each of these. Factor selection was made also according to the principle that each of these needs to allow all associations of its tested set points with those retained for the other factors.

Experiments were conducted according to an array providing 8 runs, each representing a different combination of input factor set points. Table III presents the array underlying the conducted research. Next to the set point 
number of each factor the corresponding value is indicated between brackets.

TABLE III: UTILIZED ARRAY OF EXPERIMENTS

\begin{tabular}{|c|c|c|c|c|c|}
\hline \multirow[b]{2}{*}{ Run } & \multicolumn{5}{|c|}{ Factors } \\
\hline & A & B & $\mathrm{C}$ & D & $\mathrm{E}$ \\
\hline 1 & $1(6)$ & $1(5)$ & $1(100)$ & $1(2.1)$ & $1(4)$ \\
\hline 2 & $1(6)$ & $1(5)$ & $2(63)$ & $2(1.6)$ & $2(3)$ \\
\hline 3 & $1(6)$ & $2(10)$ & $1(100)$ & $2(1.6)$ & $3(5)$ \\
\hline 4 & $1(6)$ & $2(10)$ & $2(63)$ & $1(2.1)$ & $1(4)$ \\
\hline 5 & $2(3)$ & $2(10)$ & $1(100)$ & $2(1.6)$ & $1(4)$ \\
\hline 6 & $2(3)$ & $2(10)$ & $2(63)$ & $1(2.1)$ & $2(3)$ \\
\hline 7 & $2(3)$ & $1(5)$ & $1(100)$ & $1(2.1)$ & $3(5)$ \\
\hline 8 & $2(3)$ & $1(5)$ & $2(63)$ & $2(1.6)$ & $1(4)$ \\
\hline
\end{tabular}

TABLE IV: OPTIMUM COMBINATION OF FACTOR SET POINTS

\begin{tabular}{clcc}
\hline \hline Factor & \multicolumn{1}{c}{ Description } & $\begin{array}{c}\text { Optimum set } \\
\text { point }\end{array}$ & $\begin{array}{c}\text { Value of } \\
\text { optimum set } \\
\text { point }\end{array}$ \\
\hline & \multicolumn{2}{c}{ Material: 18MoCr10, 38MoCr09 and $50 \mathrm{WCr} 11$} \\
\cline { 2 - 4 } A & Eccentricity & 2 & $3 \mathrm{~mm}$ \\
B & Abrasive concentration & 2 & $10 \%$ \\
C & Speed of lap disk & 1 & $100 \mathrm{rpm}$ \\
D & Contact pressure & 1 & $2.1 \mathrm{bar}$ \\
E & Duration of machining & 3 & $5 \mathrm{~min}$ \\
\hline \hline
\end{tabular}

This orthogonal is derived from the standard L8 $\left(2^{4}+4^{1}\right)$ one proposed by Taguchi, which has been modified such as to consider for factor $\mathrm{E}$ set point 1 as being the most important.

A line of the response table corresponds to each of the 8 runs of the array (each with a different combination of input factor set points).

The data sets obtained upon experimenting were processed by LappMaster software developed by the authors, yielding the optimum set points of the tested controlled factors (Table IV).

By setting the five factors to the thus determined optimum values, roughness $R_{a}$ is expected to be of $0.081 \mu \mathrm{m}$ for $18 \mathrm{MoCr} 10$ steel, of $0.041 \mu \mathrm{m}$ for $38 \mathrm{MoCr} 09$ steel, and of $0.042 \mu \mathrm{m}$ for $50 \mathrm{WCr} 11$ steel, respectively. These values render the lapping process robust, i.e. insensitive to noise factors.

\section{MAthematical Modelling of the OBtAined RESULTS}

Further research was aimed at establishing a mathematical relationship describing the dependency of lapped surface roughness on the five input quantities of the machining system. An equation of form (1) is proposed:

$$
R_{a}=K_{R} \cdot e c^{x R} \cdot C^{y R} \cdot v_{r}^{z R} \cdot p^{u R} \cdot t^{v R}
$$

where $e c=$ eccentricity of the retaining ring, $C=$ abrasive concentration, $v_{r}=$ relative speed, $p=$ pressure and $t=$ machining time. As can be noticed, in the above equation the relative speed $\left(v_{r}\right)[\mathrm{m} / \mathrm{min}]$ factor has replaced the lap disk speed. This substitution was required in order to simultaneously consider both lap disk speed and the speed of the retaining ring bearing the workpieces. In experiments the relative speed factor was set at $37.3 \mathrm{~m} / \mathrm{min}$.

The coefficients and exponents in equation (1) were determined by regression. Formulae (2) - (4) were eventually determined for computing the roughness of the three tested materials:

- for $18 \mathrm{MoCr} 10$ :

$R_{a}=0.009 \cdot e c^{0.208} \cdot C^{-0.865} \cdot v_{r}^{0.533} \cdot p^{-0.343} \cdot t^{-0.943}$

- for $38 \mathrm{MoCr} 09$ :

$R_{a}=0.158 \cdot e c^{0.051} \cdot C^{-0.817} \cdot v_{r}^{0.387} \cdot p^{-2.439} \cdot t^{-1.799}$

\section{- for 50WCr11:}

$R_{a}=0.05 \cdot e c^{0.075} \cdot C^{-0.905} \cdot v_{r}^{0.805} \cdot p^{-2.291} \cdot t^{-2.201}$

Fig. 4 shows the diagrams describing machined surface roughness versus relative speed, plotted for a configuration of the input quantities as provided by Table IV.

This Fig. reveals that surface roughness increases with relative speed. The higher the algebraic sum of lap disk and retaining ring speeds is, the higher the obtained roughness will be. An explanation is, that at high relative speeds the effective contact time of an abrasive grain with an asperity of the lapped surface (that needs to be flattened in order to improve $R_{a}$ ) is too short in order to allow generation of a contact tension capable of flattening by causing material flow. Because of the high relative speed the grain is transported to another point of the lapped surface and the contact of the grain with any asperity ceases before flattening occurs, being thus rendered inefficient. For this reason in surface lapping relative speeds are recommended to be small for targeted small roughness values.

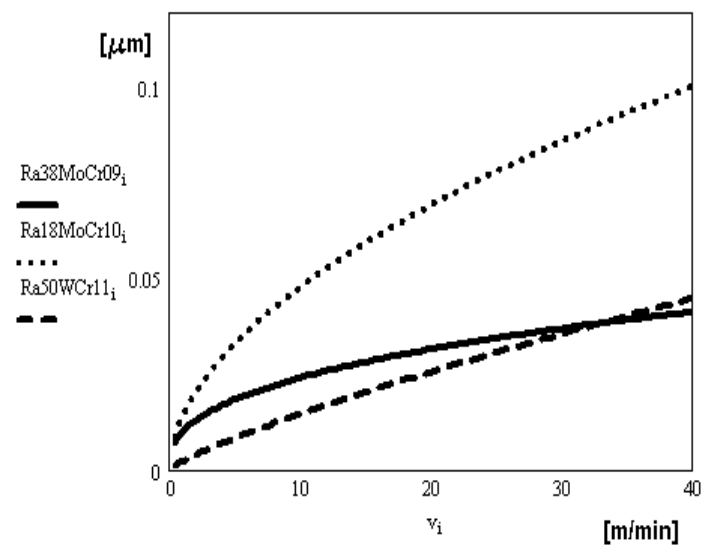

Fig. 4. Roughness vs. relative speed

TABLE V: INFLUENCE OF ROTATION DIRECTIONS ON ROUGHNESS

\begin{tabular}{|c|c|c|}
\hline Working parameters & \multicolumn{2}{|c|}{ Set point values } \\
\hline Eccentricity & \multicolumn{2}{|c|}{$3 \mathrm{~mm}$} \\
\hline Abrasive concentration & \multicolumn{2}{|c|}{$10 \%$} \\
\hline Relative speed & \multicolumn{2}{|c|}{$26.56 \mathrm{~m} / \mathrm{min}$} \\
\hline Contact pressure & \multicolumn{2}{|c|}{$2.1 \mathrm{bar}$} \\
\hline \multirow[t]{3}{*}{ Duration of machining } & \multicolumn{2}{|c|}{$5 \mathrm{~min}$} \\
\hline & \multicolumn{2}{|c|}{ Direction of rotation } \\
\hline & $\circlearrowright \circlearrowright$ & $U \cup$ \\
\hline Obtained roughness $\left(R_{a}\right)$ & 0.082 & 0.079 \\
\hline
\end{tabular}

Another stage of experimental research concerned the study of a potential influence of lap disk and retaining ring rotation directions. For this the rotation direction of the lap 
disk was maintained unchanged, while the retaining ring bearing the workpieces was rotated in the same and in opposite direction, in alternating experiments. Thus two sets of roughness values were measured, first for the two disks rotating in the same direction, and then for opposite directions. In both cases the relative speed was set at 26.56 $\mathrm{m} / \mathrm{min}$.

Tests concerning the influence of rotation direction on roughness were conducted on workpieces made from $18 \mathrm{MoCr} 10$ steel, the input parameters being set at the values given in Table $\mathrm{V}$.

Upon experimenting the two measured values of roughness parameter $R_{a}$ were very close, thus yielding the conclusion that the rotation directions of the two disks have no significant influence on the quality of lapping.

\section{CONClusions}

The paper discussed a study on the influence of machining speed on the quality of lapped surfaces. The method utilized for the optimisation of machining was robust parameter design, with the purpose of rendering the analysed system insensitive to the action of noise factors, by identifying an adequate combination of input factor set points.

Utilization of fractioned orthogonal factorial arrays of experiments lead to obtaining optimum values for the main system input quantities. The values measured by experimenting with these optimum settings of the input quantities, which ensure the robustness of machining system, allowed the plotting of roughness $R_{a}$ versus machining speed variation diagrams.

\section{REFERENCES}

[1] W. König and F. Klocke, "Fertigungsverfahren, Band 2. Schleifen, Honen, Läppen," Machining Technologies, Grinding, Honing, Lapping, VDI Verlag, Düseldorf, vol. 2, 1996.
[2] P. Deprez, P. Hivart, J. F. Coutouly, and E. Debarre, "Friction and Wear Studies Using Taguchi Method: Application to the characterization of carbon-silicon carbide tribological couples of automotive water pump seals," Advances in Materials Science and Engineering, pp. 1-10, 2009.

[3] A. Deaconescu and T. Deaconescu, "Analysis of the Impact of Robust Design on the Performance of a Plane Lapping System," Advanced Science Letters, vol. 19, no. 1, pp. 27-31, 2013.

[4] C. L. Yang, "Optimizing the glass fiber cutting process using the Taguchi methods and Grey relational analysis," New Journal of Glass and Ceramics, no. 1, pp. 13-19, 2011.

[5] X. Zheng, J. Yuan, D. Wen, and F. Lou, "Parameters optimization on the lapping process of 9Cr18 with Taguchi method," Key Engineering Materials, no. 360, pp. 158-161, 2008.

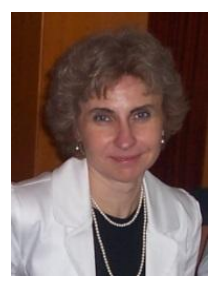

Andrea Deaconescu is a full professor at Transilvania University of Brasov, Romania, Department of Industrial Engineering and Management. She obtained her $\mathrm{PhD}$ in Industrial Engineering at Transilvania University of Brasov, Romania in 2005 and an MA in Information Science at the University of Central England at Birmingham, UK. Her main fields of competence are Robust Design of Manufacturing Systems and Communication Management. She is the author of ten books and over 90 scientific papers. Prof. Andrea Deaconescu is a member of a series of professional and scientific associations and acted as visiting professor at Bremen University, Germany, ENSAM Cluny, France and the University of Southern Denmark, Odense.

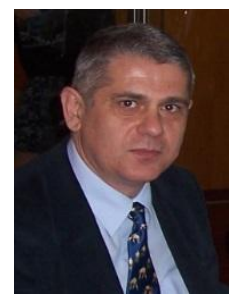

Tudor Deaconescu is a full professor at Transilvania University of Brasov, Romania, Department of Industrial Engineering and Management. He obtained his $\mathrm{PhD}$ in Industrial Engineering at Transilvania University of Brasov, Romania in 1997. His main fields of competence are Quality Ensurance and Fluidic Actuations. He is the author of 13 books and over 140 scientifc articles. Prof. Tudor Deaconescu is a member of a series of professional and scientific associations and is the director of the Festo Regional Research and Training Centre in Fluidic Drives and Automation in Brasov, Romania. 